\title{
Experimental Testing of Designated Driver Cues
}


This publication is distributed by the U.S. Department of Transportation, National Highway Traffic Safety Administration, in the interest of information exchange. The opinions, findings and conclusions expressed in this publication are those of the author(s) and not necessarily those of the Department of Transportation or the National Highway Traffic Safety Administration. The United States Government assumes no liability for its content or use thereof. If trade or manufacturer's names or products are mentioned, it is because they are considered essential to the object of the publication and should not be construed as an endorsement. The United States Government does not endorse products or manufacturers. 
Technical Report Documentation Page

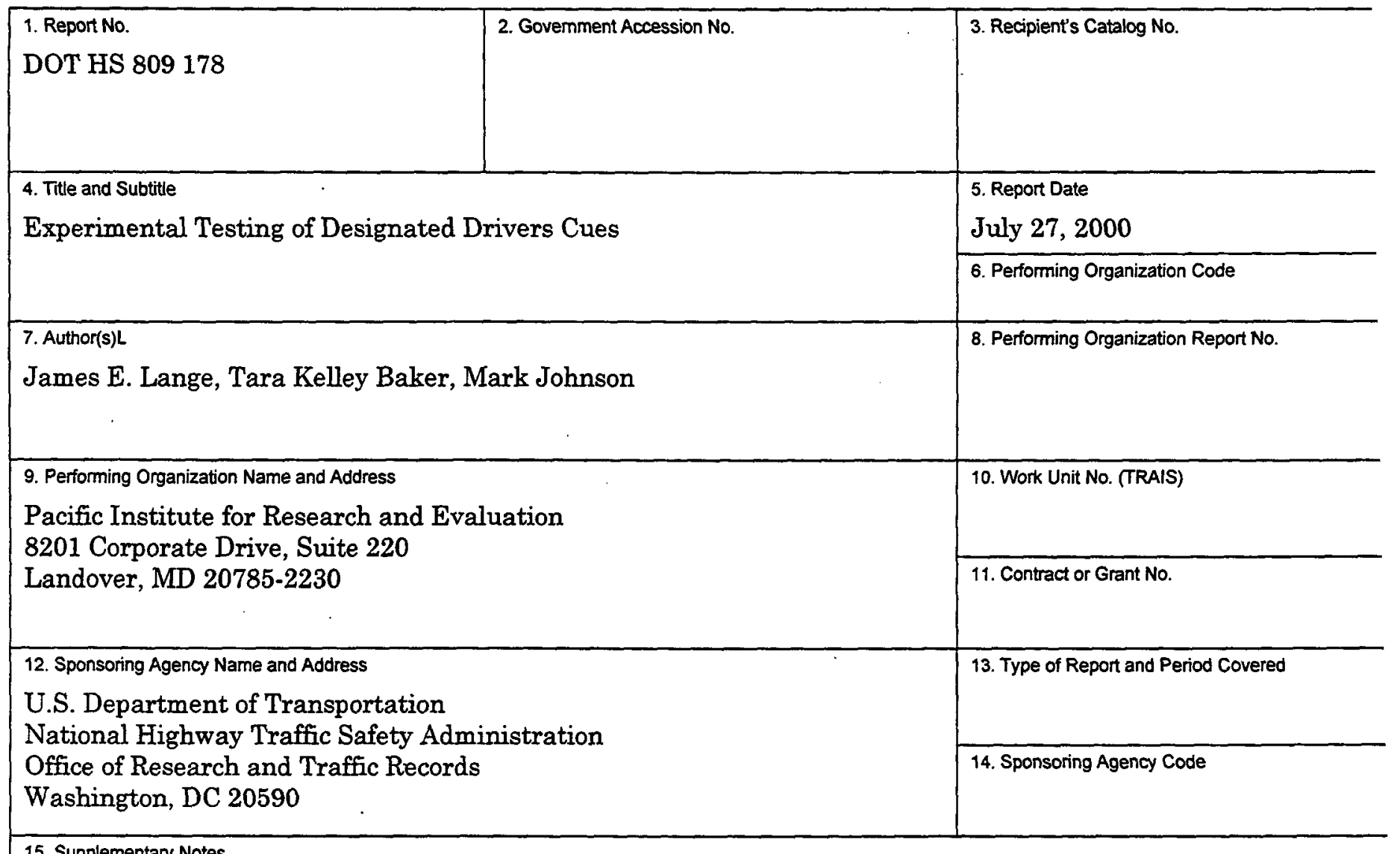

15. Supplementary Notes

Patty Ellison-Parker was the NHTSA Contracting Officer's Technical Representative for this study.

16. Abstract

In theory, the designated-driver concept holds great promise for reducing the incidences of drunk driving. It is simple, inexpensive, almost universally recognized, and generally positively regarded by the U.S. population as a means for avoiding drunk driving. In practice, however, research has shown that implementing the designated-driver concept is often flawed. This pilot study was designed to begin to address the factors that may impede proper implementation of the designated-driver concept. One possible impediment was postulated to be the "mindlessness" (Langer, 1989) with which people approach the drinking location. In this case, designated drivers are not considered because travel routines do not elicit alternatives into consciousness. Cueing the concept at an appropriate point for designation of the driver was a possible way to counteract this mindlessness and, thus, activate the designated driver concept.

The experiment was conducted at the San Ysidro border crossing. There, on weekend nights, thousands of young San Diegans cross into Tijuana to patronize bars and clubs and to engage in binge drinking (Lange \& Voas, 2000). Groups of crossers were sampled as they arrived on the Mexico side of the border and they were offered incentives to check in upon their departure from Tijuana. Groups were randomly assigned to either a cue or neutral condition, where cued participants were asked to identify their designated driver. Alcohol breath tests were administered to all participants when arriving and when departing. A total of 404 participants checked in upon their return. Results showed that merely cueing subjects about the use of a designated driver is insufficient to change drinking behavior. Additional interventions are presented that could also be attempted at the Tijuana border.

\section{Key Words}

Designated driver; DUI; DWI; drinking and driving; binge drinking; crossborder drinking
18. Distribution Statement

NTIS Phone number and NHTSA web site

\begin{tabular}{|l|l|l|l|l|l|l|l|}
\hline 19 Security Classif. (of this report) & 20. Security Classif. (of this page) & 21 No. of Pages & 2rice & & \\
\hline
\end{tabular}




\section{Executive Summary}

In theory, the designated-driver concept holds great promise for reducing the incidence of drunk driving. It is simple, inexpensive, almost universally $3 . . . j n i z e d$, and generally positively regarded by the U.S. population as a means for avoiding drunk driving. In practice, however, research has shown that implementing the designateddriver concept is often flawed. To function properly, groups of drinkers must commit to three actions: (1) the group must designate a driver before starting to drink, (2) the designee must abstain from drinking, and (3) the designee must fulfill his or her responsibility to be the driver. Failure at any of these three stages of implementation could result in potentially impaired drivers either claiming to be the designated driver or usurping the role of the designated driver.

This pilot study was designed to begin to address the factors that may impede proper implementation of the designated-driver concept. One possible obstacle was hypothesized to be the "mindlessness" with which people approach the drinking location. Use of designated drivers is not considered because travel routines do not elicit alternatives into consciousness. At this stage, attitudes about the concept are not critical since they are only relevant if the concept is activated. Cueing the concept at an appropriate point for designation of the driver was a possible way to counteract this mindlessness and, thus, activate the designated driver concept. Once activated, varying attitudes and associated concepts would likewise be activated. However, whether or not individuals would use a designated driver was uncertain. Still, without such activation either through external cues or through internal sources, designation of an unimpaired driver would often not be made.

This experiment was conducted at the San Ysidro, U.S./Mexico border crossing. There, on weekend nights, thousands of young San Diegans cross into Tijuana to patronize bars and clubs and to engage in binge drinking (Lange \& Voas, 2000). Most park their vehicles on the U.S. side and walk across the border. An existing National Institute on Alcohol Abuse and Alcoholism-funded longitudinal survey is underway, sampling groups of crossers as they arrive at the border and offering them an incentive to check in upon their departure from Tijuana. Alcohol breath tests are administered to participants when arriving and when departing. Though conducted on different nights than the existing longitudinal survey, this intervention built upon our experience with the existing survey. Further, the methods used recruited whole groups and, thus, offered an opportunity to study the effect of a designated driver on passengers' blood alcohol concentration levels (BACs).

The cue was a question asked orally to a randomly assigned set of participant groups. The question, "Who will be your designated driver tonight?" was posed to half of the randomly selected groups. Observations about the manner of designation and the method of selecting participants were recorded. Fifty-six groups (207 participants) were 
assigned to the neutral condition, and 65 groups (248 participants) were assigned into the cue condition. Of these, 404 participants checked in upon their return. Results of the intervention included-

- $87.8 \%$ of the cued groups indicated the designated driver without discussion, which suggested that the designated driver had been determined beforehand. $10.2 \%$ had not determined the designated driver until after being cued, and $2.0 \%$ indicated that the designated driver would be determined in Tijuana.

- Cued and noncued drivers did not differ significantly in their drinking.

- Upon return, only 1 of the 104 returning groups did not have a driver who identified himself or herself as a designated driver. Some groups were large enough to have more than one designated driver.

- Thirty-three (33) of the designated drivers, both cued and noncued, had been drinking. The average returning $\mathrm{BACs}$ for the designated drivers were between .05 and .06 for men and .04 for women.

- Participants who were initially assigned the role of designated driver but did not act as the designated driver upon return had significantly higher BACs than did participants who were both initially assigned that role and acted as the designated driver upon return.

- Drivers' BACs did not significantly differ between the cued and noncued groups. Further, BACs of male drivers did not differ from BACs of female drivers

- Analysis of returning passengers (but not drivers) also failed to reveal significantly different BACs between the cued group and the noncued group. However, the average returning BAC of male passengers was significantly higher than for female passengers. The interaction between cue and gender did not approach statistical significance. 


\section{Table of Contents}

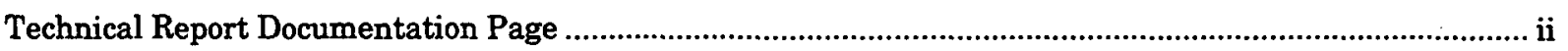

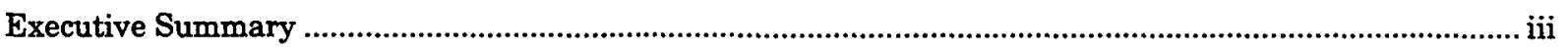

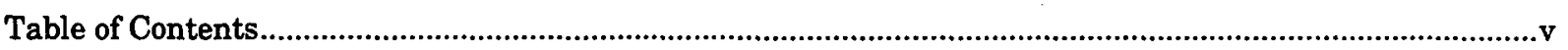

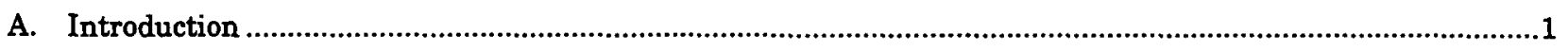

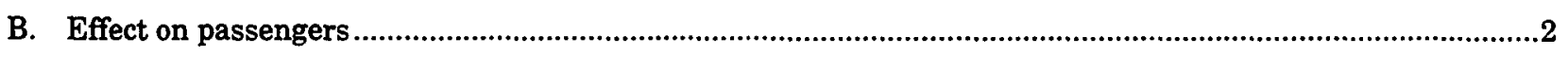

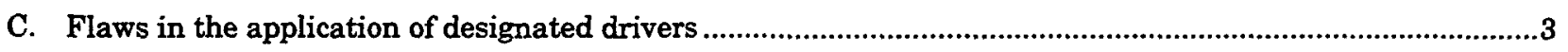

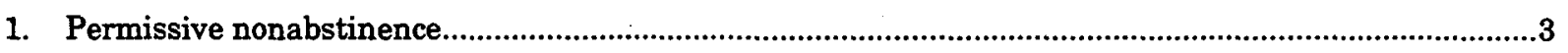

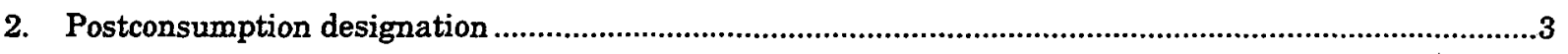

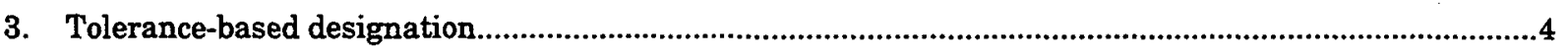

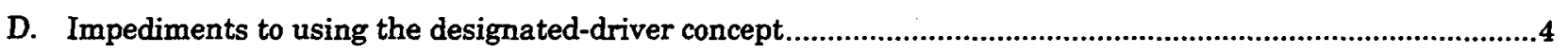

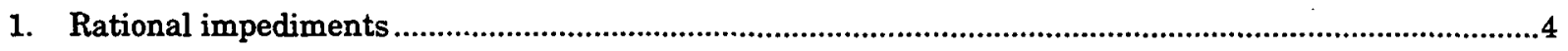

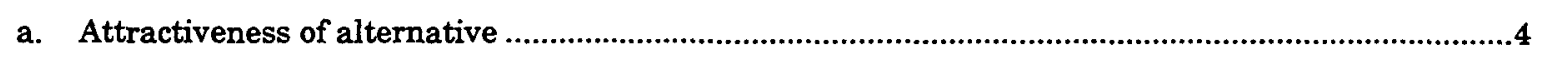

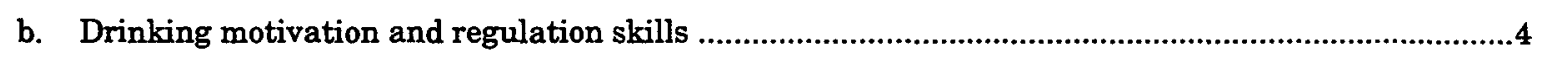

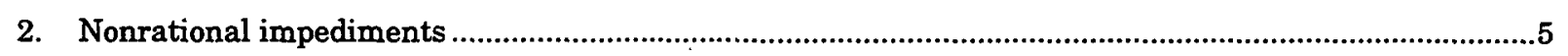

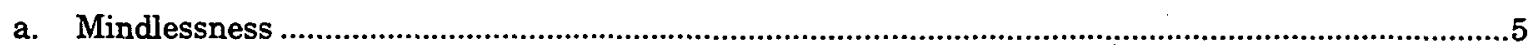

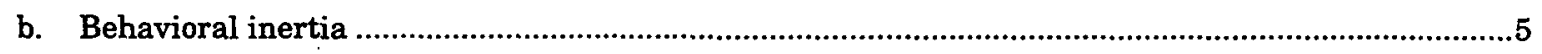

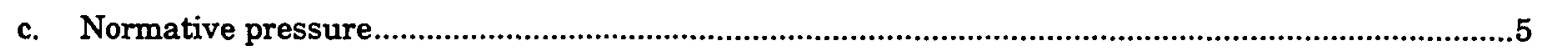

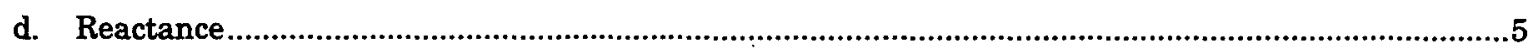

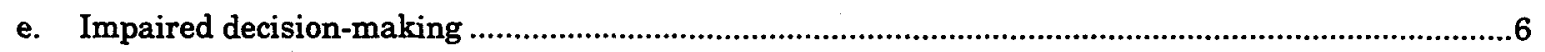

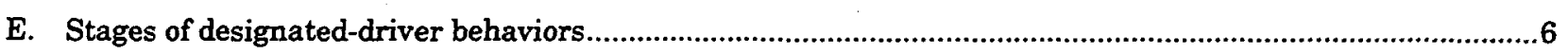

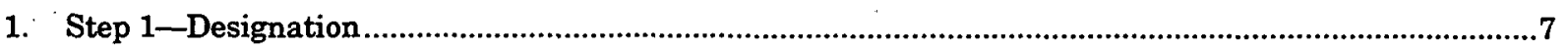

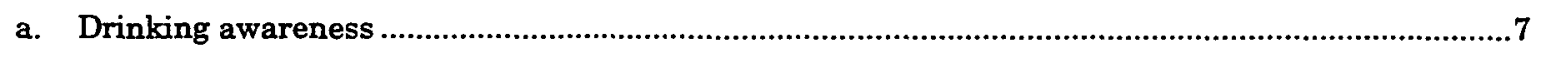

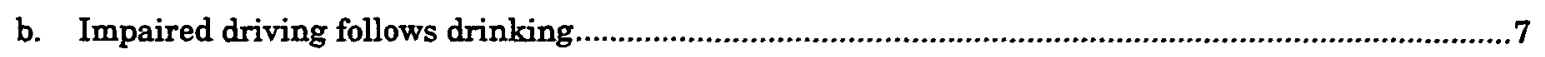

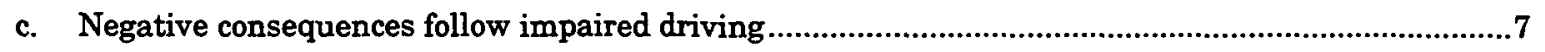

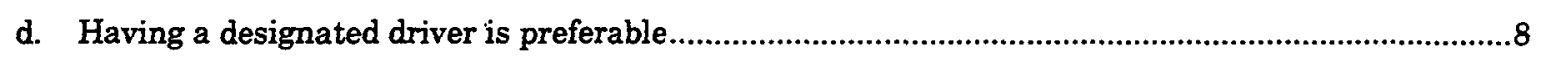

2. Step 2-Requirements placed on designated drivers limiting use of alcohol...........................................

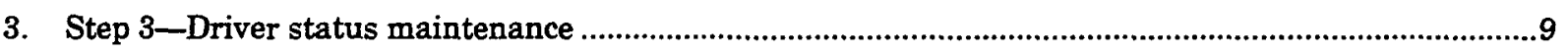

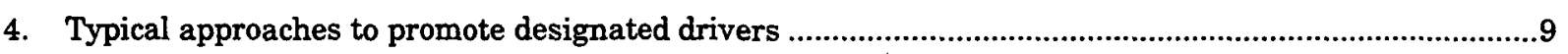

a. Novel approaches to increase the use of designated drivers............................................................10

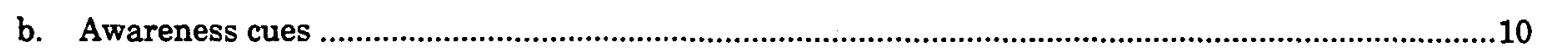

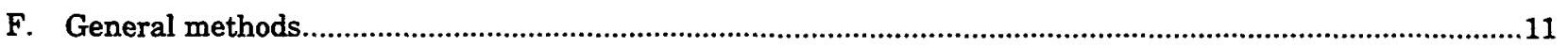

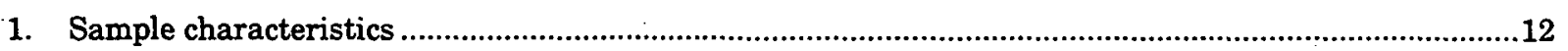

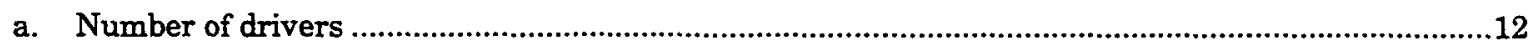

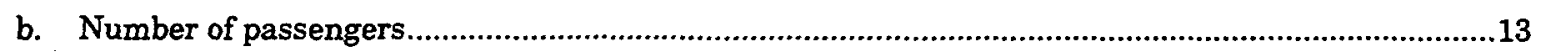

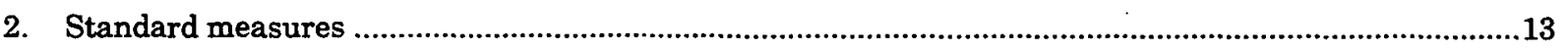

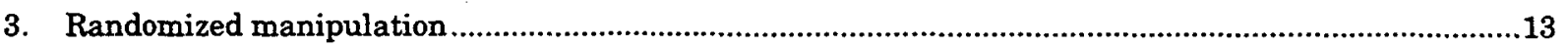




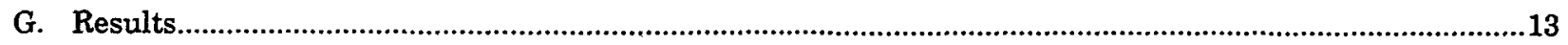

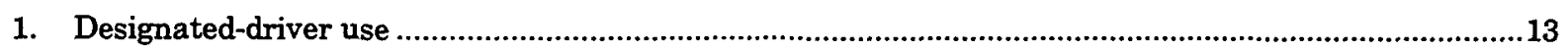

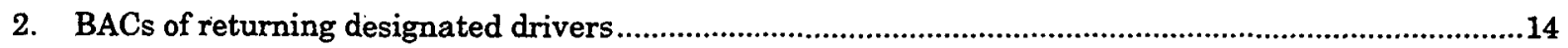

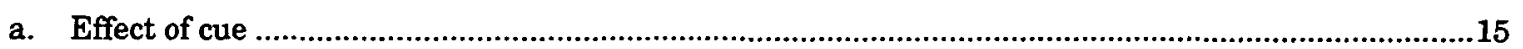

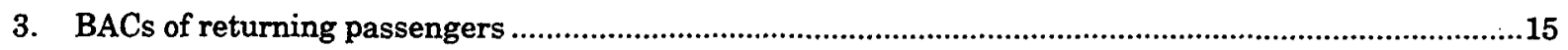

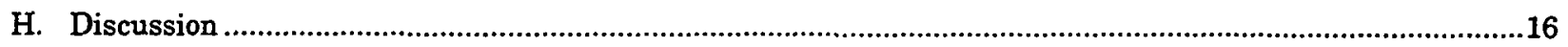

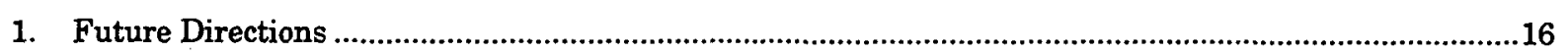

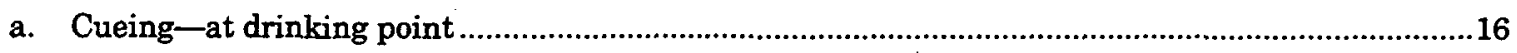

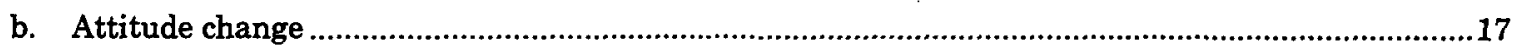

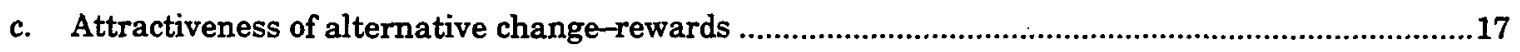

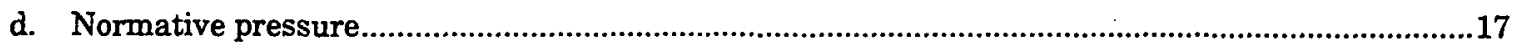

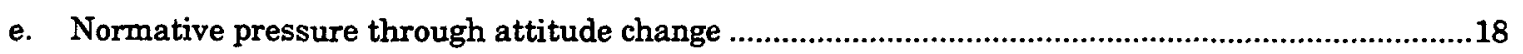

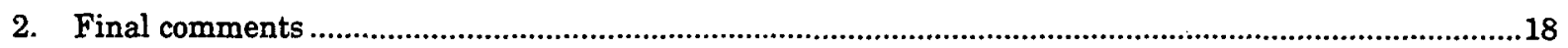

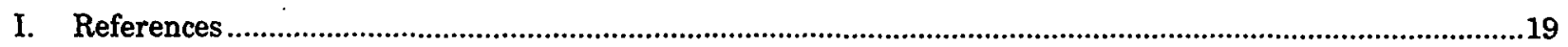




\section{A. Introduction}

The most effective social policies for the control of alcohol-related traumatic injuries and the problems related to alcohol addiction are probably programs that reduce alcohol consumption. Also important are policies directed at reducing problem behaviors resulting from excessive consumption. These policies can help make those behaviors less threatening to the safety and health of the drinker and society. This harm reduction approach, which has been popular in industrial nations abroad, is receiving increased attention in the United States (Single, 1996). In his review of harm reduction programs, Single notes that they may be particularly appropriate when they focus on heavy drinking occasions. Here, his work indicated that such occasions were closely related to alcohol problems.

Single includes in his review several training programs and preventive education aimed at persuading heavy drinkers to observe safe-drinking limits. These programs are a mixture of direct attempts to reduce consumption with procedures that reduce the harmful results of heavy consumption. Programs clearly fitting the harm reduction paradigm are "safe-ride" and "designated-driver" campaigns that focus mostly on reducing the consequences of heavy drinking rather than reducing the amount consumed. Ross (1992) pointed to the problems in the United States caused by the fact that most commercial drinking establishments (and most friends' homes as well) must be reached by automobile. Consequently, he concluded that drinking and driving becomes almost inevitable. This supports two harm reduction concepts. The use of "safe rides" where the drinking establishment or a public organization provides transportation home for individuals too impaired to drive safely, and the "designateddriver" concept where one member of a group attending a drinking event refrains from consuming alcohol in order to provide a safe ride home for others in the group.

Several communities have organizations that provide rides to individuals who have been drinking and who believe they cannot drive safely home. Harding, Apsler, and Goldfein (1998) surveyed 335 such ride-service programs in both large and small communities across the country. They discovered that most of these programs provided free transportation for impaired drinkers but only 15 percent provided a method for returning the drinkers' vehicles to their homes. This major limitation apparently accounts for the low usage of the safe-ride programs.

Apsler, Harding, and Goldfein (1987) conducted a national study of commercial establishments that claimed to support designated-driver programs, usually by posting notices urging customers to adopt the program's practices and providing free soft drinks to designated drivers. These investigators sampled 40 of the 431 drinking establishments claiming to support designated-driver programs and found that customer participation in these programs was low.

Both concepts-safe ride and designated driver-can help minimize the highway safety consequences of heavy drinking. Alternatively, it must also be recognized that one of the informal controls on the amount of drinking is the individual's perception of the risk of crash involvement or arrest if driving while impaired. A designated driver may also sense group pressure to limit consumption. The availability of a substitute driver, either through a safe-ride program or through a designated-driver program, can 
act to remove these constraints. Thus, heavy drinkers who know they will be a passenger may consume more than if they had to drive. This, in turn, could cause additional harm due to the increased dependence on alcohol or the increased risk of non-traffic-related trauma (e.g., falls, fires, or violence). Harding and Caudill (1997) conducted telephone and barroom surveys of drinkers who had been transported by a designated driver. Their respondents reported small, but significant, increases in their drinking outside the home when a designated driver was available. Thus, evaluators of designated-driver programs need to consider two issues: (1) the extent to which these programs reduce the crash risk of drivers being transported by designated drivers and (2) the program's potential for increasing consumption that results in increased drinking-related problems in nontraffic safety areas.

\section{B. Effect on passengers}

As noted, one of the most serious threats to the designated-driver concept is the fear that passengers of designated drivers will drink more. DeJong and Wallack (1992) felt that this potential was problematic enough to suggest that designated-driver programs should only be advocated when used with other environmental interventions that would influence alcohol consumption. They claim that encouraging the use of designated drivers sends a "mixed message" to people as it appears to condone heavy drinking. They cite others who go as far as to suggest that designated driving is tantamount to "enabling." However, they also acknowledge that there is no empirical evidence to support this fear. Wagenaar (1992, p. 444) also notes the lack of data on this point, stating that "We urgently need controlled studies of designated-driver programs, including direct observation data on the specific patterns of response of drinkers to the availability of a designated driver."

Research on this issue is difficult because the use of designated drivers naturally covaries with the plans to drink and the characteristics of the group, so strictly observational investigations would offer few insights. Shore, Gregory, and Tatlock (1991) attempted to measure passenger drinking through self-reports from members of a fraternity. They found no statistical difference in reported drinking when a designated driver was available.

There may even be some reason to believe that heavy drinking may even be suppressed by the presence of a designated driver. DeJong and Wallack (1992, p. 432) suggested this themselves though they do not seem to consider it significant. They stated that a designated driver "can legitimize the appropriateness of not drinking alcohol at social events." This is an intriguing theoretical position. Other research on group drinking has suggested that the presence of peer drinking may increase group members' consumption (Caudill \& Marlatt, 1975; Leid \& Marlatt, 1979; Collins, Parks, \& Marlatt, 1985; Reid, 1978; Cooper, Waterhouse, \& Sobell, 1979). However, normative pressure is known to be most effective when it is unanimous. The presence of even a single countervailing example can prevent conformity (Asch, 1951). Therefore, if members of the group had wished not to drink heavily, then the presence of an abstaining driver may provide the social support needed to refrain from deviating from these plans. 


\section{Flaws in the application of designated drivers}

\section{Permissive nonabstinence}

Almost from the first implementation of the designated-driver programs, researchers have noted that many misapply the concept. Apsler (1989) identified one such flaw: some designated drivers and bars facilitating their use do not believe it important that the driver abstain from drinking but, instead, merely limit consumption. Shore et al. (1991) also found that designated drivers often drank though a majority did drink less. Knight, Glascoff, and Rikard (1993) found that, in focus groups of college students, participants would talk "about widely varying alcohol consumption limits" for designated drivers.

Fell, Voas, and Lange (1997) found that the BACs of designated drivers returning from bars were indistinguishable from those of nondesignated drivers. Clearly, one would have expected lower BACs from those claiming to be designated drivers. However, as noted in other studies, implementing the designated-driver concept does not seem to match the most optimal way to avoid DUI for many people. Other indications of the impediments were suggested from analyses of focus groups and telephone surveys of drivers (Lange, Voas, \& O'Rourke, 1998). Lange et al. primarily highlighted the flaws of definition found among the users of the designated-driver strategy. Common shortcomings are discussed below.

Of those sampled, $35.8 \%$ did not include the concept of abstinence for the designated driver in their definitions. The heavier drinkers of both genders were even more permissive. Although most would limit their drinks to only one, many found two or more drinks an acceptable limit for the designated driver. Some were even more permissive. The television show 48 Hours (CBS, 1/14/99) illustrated this when they interviewed a woman whose speech was slurred at the Tijuana-San Diego border. She said that she was the "sober driver." She then proceeded to list the drinks she had consumed that night, saying "Like six drinks. Like three poppers and like four shots." In Tijuana, poppers of Tequila are poured directly down a patron's throat from the bottle by a bartender.

\section{Postconsumption designation}

Another flaw is the designation timing. Glascoff, Knight, and Jenkins (1994) found that a substantial proportion of their college student sample did not agree with the statement, "Designated drivers are usually selected BEFORE drinking begins." However, the wording of their questions did not clearly indicate whether participants were rating beliefs or observations. Regardless, it points to the problem that some do not properly use the concept.

In the Lange et al. (1998) study when respondents were asked to define a designated driver, only $55.7 \%$ of those sampled specifically stated that the driver would be selected before drinking. Again, heavy drinkers were the most likely to omit the predrinking designation. After drinking, groups of friends often attempt to assess who is the least impaired among them. Then, they label the selectee as the designated driver. This approach is fraught with danger as it provides no assurance either that a sufficiently unimpaired driver will be available or that the group will have appropriately chosen the least-impaired individual. Social pressures may also preclude 
a nonbiased assessment of impairment within a group of drinkers as some may be reluctant to admit to their level of impairment or the vehicle owner may be selected by default.

\section{Tolerance-based designation}

Focus group discussions on this topic yielded another flawed process in designation: tolerance-based designation. This is typified by statements such as "I am always the designated driver because I can hold my liquor" (paraphrased). Bold claims that "...alcohol does not affect me..." were also espoused by some people in groups. The problem is that tolerance assessment is probably based upon the presence of (or lack of) gross, observable types of impairment. However, aspects of cognitive abilities associated with safe driving may be affected before coordination deficits (Moskowitz, 1973; Moskowitz, Burns, \& Williams, 1985), so it is unlikely that the driver is more impaired with respect to driving skills than he or she believes. Regardless, tolerancebased designation is not the intended meaning behind the public service campaigns to use a designated driver.

\section{Impediments to using the designated-driver concept}

Impediments to using the designated-driver concept can be categorized into rational and nonrational psychological factors. The rational-nonrational distinction is admittedly artificial, but still useful. Rational implies that an individual or the group consciously considered alternatives and chose the option with the most positive and least negative attributes. This does not mean that a rational process will yield the most functional outcome as it is limited to available schemas. Nonrational implies that an individual or group did not use or discounted available schemas in spite of his or her relevance to the situation. It may also include using heuristics instead of a mindful consideration of the contingencies. This distinction loosely matches social-cognitive concepts such as central and peripheral routes to persuasion (Petty \& Cacioppo, 1986), heuristics versus systematic processes (Chaiken, 1980), and the attribution decision distinctions outlined by a number researchers (see Kelley \& Michela, 1980).

\section{Rational impediments}

\section{a. Attractiveness of alternative}

If the designated-driver concept is considered, it may not be implemented because it is seen as an alternative that is less attractive than drinking and driving (e.g., Turrisi \& Jaccard, 1992). As discussed above, for some, the prospect of drinking and driving is not laden with many negative associations. Therefore, the inconvenience, stress, and self-limiting aspects of being a designated driver may be sufficiently unattractive as to make drunk driving the logical choice. Those who feel this way may be a particularly difficult group of individuals for intervention because it would require changing attitudes about drunk driving.

\section{b. Drinking motivation and regulation skills}

Choosing someone as the designated driver is insufficient to prevent drunk driving. The designee must limit drinking. This means when offered a drink, the designee must refuse it. Again, the refusal decision can be rationalized by considering the positive aspects of drinking as related to the responsibilities of driving. Because the designee is 
out with friends who are drinking, it is more than likely that many, if not most, will hold a positive view of drinking alcohol. Therefore, it may not be surprising that they will often exhibit a motivation to drink.

\section{Nonrational impediments}

a. Mindlessness

Perhaps the most pervasive impediment is the lack of attention to the situation as it unfolds with respect to drinking and driving. The literature on drinking and driving has focused on the logical elements of a mindful decision by potential drinkers and potential drivers (e.g., Turrisi \& Jaccard, 1992). However, many probably do not ever consider alternatives as they are acting in an automated or a "mindless" (as Langer, 1989, put it) fashion. When people follow routine and well-learned behaviors, conscious decision-making is not activated. For instance, when a person decides to go out drinking, he or she may consider where to go, but the routine aspects of how (i.e., to drive or not to drive) may never be considered. Instead, he or she merely gets in a vehicle and goes. This is a nonrational process because routine drives the decision, not a careful consideration of alternatives.

\section{b. Behavioral inertia}

Once routine has taken over, behavioral inertia plays a significant role in maintaining impediments to designated-driver usage. If, for instance, due to lack of planning, a group of friends meet at the bar, each may have a vehicle making it far more inconvenient to use a designated driver. McKnight, Lange, and McKnight (1995) pointed out that the decisions (or not considering alternatives) made early in the evening tended to lock people into a set of circumstances that made drunk driving highly probable and selecting alternatives unattractive.

\section{c. Normative pressure}

Caudill and Marlatt (1975) demonstrated that, in laboratory environments, subjects will drink more when in the presence of a drinking confederate. Other observational research has also found a relationship between group size and drinking rates and quantities (Hennessy \& Saltz, 1993; Sykes, Rowley, \& Schaefer, 1990; van de Goor, Knibbe, \& Drop, 1990). Groups behave in other ways that encourage drinking, both with overt pressure (Bruun, 1959; Room, 1975; Aitken, 1985; van de Goor et al., 1990) and through actions like buying rounds of drinks. The presumption here is that individuals are influenced by the mere presence of other drinkers. It is not likely, however, that the presence of others will provide any information that can be used in a rational decision process. Instead, it merely provides normative pressures. If this pressure is placed upon the designated driver, then he or she may fail to remain abstinent.

\section{d. Reactance}

The designated driver agrees to forego the freedom to drink. The mere limitation of freedom can evoke negative feelings, thus producing a tendency to react against such limitation. Brehm (1972) called this psychological reactance and demonstrated several occurrences. It can be reasonably assumed that, during a drinking event, some designated drivers may be motivated to act against the limitation of their commitment and consume alcohol. 


\section{e. Impaired decision-making}

Alcohol has been shown to reduce the attention span (Moskowitz et al., 1985; Binder, 1971; Billings, Gerke, \& Wick, 1972) and the range of concepts or consequences considered (Hull, Levenson, Young, \& Sher, 1978). Diminishing capacity to consider concepts may affect one's ability to access inhibitory cues (such as consequences or sanctions), thus increasing the probability of reckless actions (Lau, Pihl, \& Peterson, 1995; Steele \& Southwick, 1985). If members of a group experience these effects, then the decision to limit drinking and maintain driver status for the designee may be seriously jeopardized.

\section{E. Stages of designated-driver behaviors}

To fully understand the use and misuse of the designated-driver concept, it is useful to parse the implementation into discrete stages or decision points. Specifying stages for proper implementation helps identify areas for intervention. The process of using a designated driver falls into three stages: designation, limitation of alcohol, maintenance of driver status. These stages presume that drinking will be a group activity and that ride-sharing is possible. Other, more subtle limitations at each stage impede proper implementation of the designated-driver concept. The following paragraphs discuss these three stages in the order that they must occur for proper implementation. Figure 1 illustrates the three stages, or decision points, necessary for implementing the designated-driver concept and the possible impediments to implementing them successfully.

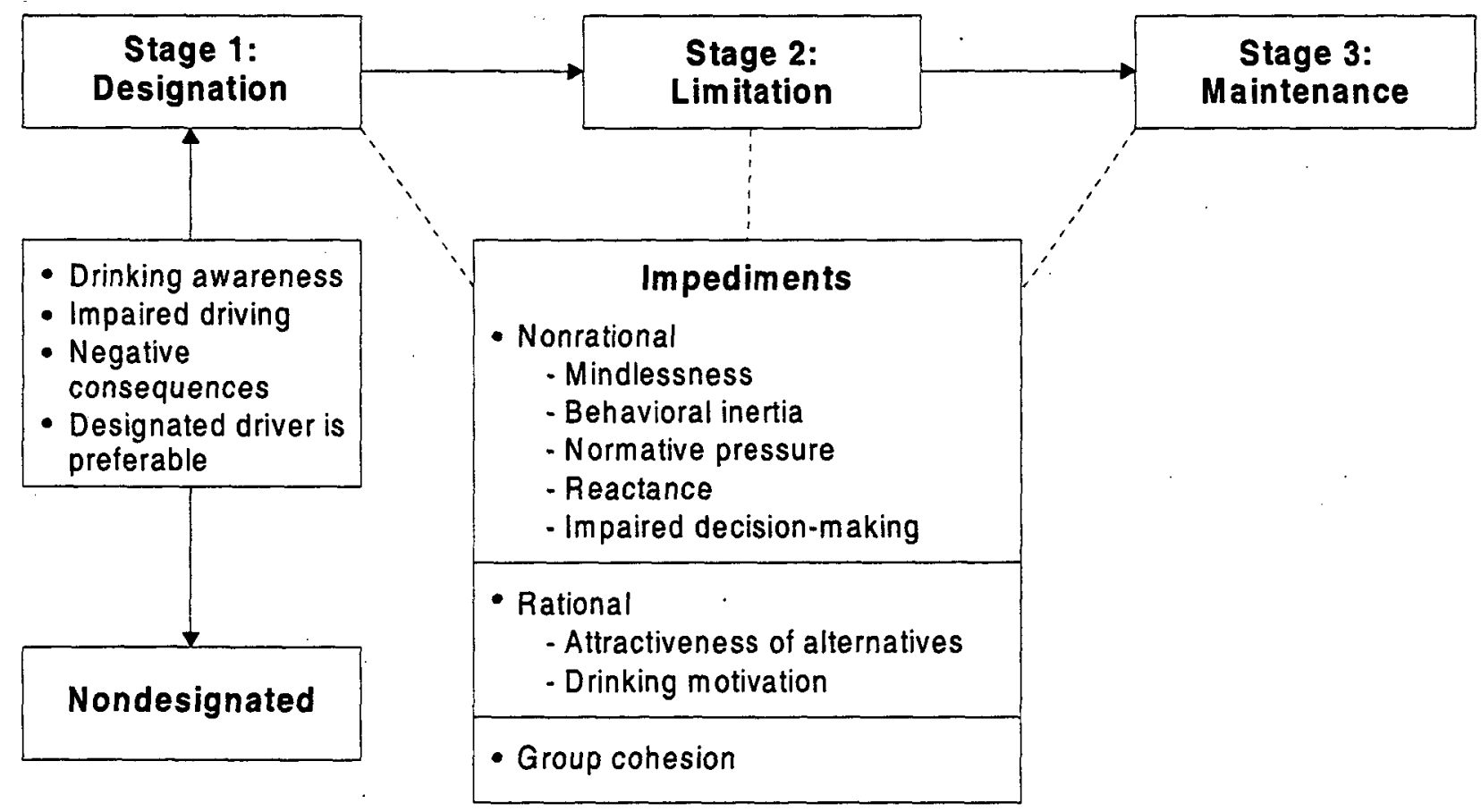

Figure 1. Stages to proper implementation of the designated-driver concept

Each stage in this progression may be influenced by a set of impediments. Nonrational impediments, mindlessness, and behavioral inertia are most clearly those impeding the success of Stage 1, Designation, of a driver. Rational impediments, such as attractiveness to the alternative of not drinking or limiting drinking and motivation 
to drink, most logically arise during Stage 2, Limitation. Further, normative pressure from group drinking and psychological reactance may yet be another impediment at this stage. Driver Maintenance (Stage 3) may be influenced by flawed or impairment detection skills, decision-making, and poor group cohesion.

\section{Step 1-Designation}

Even though a driver must be designated, perhaps the most persistent pitfall to using the designated-driver concept is failing to assign the driving responsibility before initially drinking. For designation to occur before drinking, members of the group must know (1) that drinking will occur, (2) that impaired driving may follow the drinking activity, (3) that negative consequences may result from impaired driving, and (4) that using a designated driver is preferable to incurring negative consequences.

\section{a. Drinking awareness}

Occasionally, people find themselves in situations where drinks are offered unexpectedly. Without an awareness that drinking is possible, the concept of designating a driver will not be considered as it would be outside the universe of relevant options. Activation of the designated-driver concept should only occur when associated concepts (namely, impaired driving) are activated as well. In interviews, McKnight and his colleagues (1995) found that a subset of participants reported they were surprised by either the presence or the amount of alcohol at an event that they attended before their drinking-and-driving experience. Since using a designated driver often requires coordination of travel plans with friends, without prior knowledge of the possibility of drinking, it becomes difficult for people to use a designated driver.

\section{b. Impaired driving follows drinking}

Although many people know that alcohol will be consumed, they do not believe that impaired driving may follow. Preliminary focus groups conducted by our lab indicated that some believed they were immune to the impairing effects of alcohol. McKnight et al. (1995) found similar instances. One interviewee stated that he could not get drunk if he drank while driving, as he believed that the concentration needed to drive impeded impairment. Others simply believed that they could control a vehicle after drinking, and a few reported that they drove "better" after drinking. Regardless of the validity of these beliefs, if one does not believe that alcohol will cause impairment, then one will not consider designating a driver. An extension of this belief (discussed below) is the designation of a driver with the highest perceived tolerance to alcohol.

\section{c. Negative consequences follow impaired driving}

Although potential drivers may be aware that drinking will occur and may lead to impaired driving, another critical component-negative attitudes and beliefs about impaired driving-may keep them from activating relevant alternatives. Such negative attitudes may come from social norms, which among some groups pressure individuals not to drink and drive. Alternatively, it could come from a belief that there is a risk of injury or arrest associated with drinking and driving. Of course, there are countervailing beliefs and attitudes as well. Experience may have taught the driver that there are not (or have not yet been) any negative consequences to driving while impaired. Alternatively, one may hold the belief that alcohol-impaired driving is risky, 
but social pressures against demonstrating fear may stifle concern over the negative consequences.

\section{d. Having a designated driver is preferable}

Finally, if the first three conditions are met, generating alternatives to drinking and driving may occur. Then, if the designated-driver concept is cognitively available, it may be activated into consciousness and weighed against other alternatives to drinking and driving that may have also been activated. This process will require the individual to assess his or her attitudes about using a designated driver. Some may associate a designated driver with negative consequences. One of the most obvious is that the designated driver cannot participate in the drinking activity, at least to the same level of their friends. It also ties friends together with respect to mobility, limiting options. Further, there may be social norms against using a designated driver as it is a concept associated with the "adult establishment." It also forces a public admission, at least among friends, that members of the group intend to drink. Social norms may preclude this admission for some.

Knight et al. (1993) also noted that in a sample of college students some expressed feelings of stress and anxiety over being a designated driver. They apparently felt that the designated driver has some responsibility for the welfare of the drinking members of the group. This included caring for and interacting with severely impaired individuals.

If the fourth condition for making a designation is met, then a group may consider using a designated driver. They can then negotiate the designation of a driver with their friends. How the selection is made is interesting and important. However, it does not outweigh the importance of need recognition before drinking as our research has demonstrated that a significant impediment to the successful implementation of the designated-driver concept is the predrinking designation. That many designate the driver after drinking is an indication that the option may not have been in their awareness before the drinking occasion.

\section{Step 2-Requirements placed on designated drivers limiting use of alcohol}

After designating a driver, perhaps the most important behavioral action that must occur is for the designated driver to limit his or her drinking and other impairing substances. There is tremendous disparity among individuals about this limitation. Lange et al. (1998) found that, among a random telephone sample of California residents, recognition of the designated-driver concept was almost universal (see also The Roper Organization, 1991). Nonetheless, when asked to provide a definition, a substantial portion of the respondents did not mention abstinence. Specifically, $64.2 \%$ of the respondents stated that the designated driver should not drink anything within 4 hours, $19.5 \%$ thought one drink was acceptable, and about $11 \%$ reported that a designated driver could have two or more drinks before driving.

Limiting alcohol consumption is influenced by several factors. Some designated drivers are selected because they do not drink alcohol, so limiting consumption for them does not require any unusual set of behavioral responses. However, for others, being the designated driver means behaving in an atypical manner in a drinking situation. 
Successfully limiting drinking may depend on some planning or forethought by the drinker. Researchers, Werch and Gorman (1988; also Werch, 1990), have identified a variety of internal and external behavior strategies for limiting consumption among a sample of college students. According to Werch and Gorman, students naturally attempt to control their alcohol consumption. These attempts at self-control are related to specific alcohol-consumption levels and alcohol-related problem status. Students experiencing alcohol-related problems or drinking regularly or heavily were likely to practice self-control strategies; however, the strategies most often used were restrictive and required less forethought. For example, strategies aimed at controlling time (e.g., drinking after a certain hour), food (e.g., eating before drinking), self-reinforcement (e.g., reward), and punishment are most indicative of self-control by heavy drinkers. These more restrictive strategies appear to rely little on planning; rather, these strategies are used immediately during the drinking episode (i.e., eating before or during drinking) or as an afterthought (i.e., reward or punish for failure to limit). With respect to driving, McKnight et al. (1995) have shown that without planning, heavy drinkers are almost committed to drinking and driving once they arrive at the drinking event. Thus, planning how the designated driver intends to limit his or her consumption may be as essential as designating the driver.

\section{Step 3-Driver status maintenance}

In addition to limiting alcohol intake, the designated driver must drive the group's members to their homes. Though this may seem obvious, focus groups (Lange et al., 1998) and interviewees (McKnight et al, 1995) indicate that there is often resistance to having someone else drive their vehicle. If the owner of the vehicle can convince the designated driver that they are "okay to drive," the designated driver may relinquish his or her role. This poses serious risks since it relies on perceptual cues, which are often inaccurate, to assess the impairment level of the vehicle's owner. However, even relatively low levels of alcohol may affect the judgment of the owner, thus making selfassessment of impairment suspect. Another factor is the cohesiveness of the group throughout the evening. Sometimes, the group's members will leave with people other than those with whom they arrived. The driver must stay with those he or she has agreed to take home or, at the very least, ensure that his or her passengers have found another safe ride home.

\section{Typical approaches to promote designated drivers}

Typically, designated-driver interventions have relied on two channels for change: information and cues. Information campaigns have sought to increase awareness of the concept (e.g., DeJong \& Winsten, 1990), and cues, often placed in bars, are intended to activate the existing knowledge structure at the appropriate time (Simons-Morton \& Cummings, 1997). There is some evidence that the information has actually been disseminated. Two Roper organization surveys in 1989 and 1991 showed strong recognition and support of the concept in the United States (The Roper Organization, 1991). Lange et al. (1998) found that most respondents in a random digit-dialing (RDD) survey knew some aspects of the definition of a designated driver. Though many definitions contained flaws, the general awareness, in spite of flaws in conceptualization, speaks well for the successful dissemination of information. However, the lack of proper use means that other factors aside from conceptual availability are important. 
The other main channel for effecting use is the placement of cues such as stickers or placards, mostly at locations of alcohol sales, to remind patrons to designate a driver. These cues-usually a brief slogan like "Before you celebrate, designate"-are not intended to explain how to use a designated driver. They merely attempt to activate the presumably available concept, bringing it into the awareness of the patrons. The slogan presented as an example above would be completely meaningless without some background knowledge of the concept of designated drivers.

A slogan's effect may be weakened by its position in the drinking-event timeline. They are usually found at bars or restaurants and, therefore, do not affect the arrivaltransportation decisions of patrons. This means that some groups of friends who see these cues will have arrived separately at the establishment, thus making it less likely that they would use a designated driver. They also do not combat the other barriers to implementation such as reactance, unattractiveness of alternatives, and drinking motivations.

\section{a. Novel approaches to increase the use of designated drivers}

Given that the designated-driver concept holds great promise for lowering the incidence of drunk driving but is not fully used by the general population, it is worth investigating other methods for promoting its use. Such methods should address as many of the identified impediments as practical. These approaches should build on the existing health-behavior interventions tested for other topics. Additionally, the careful description of the stages, and their impediments, highlight areas where simple interventions may effectively change behavior. It also helps identify impediments that are not amenable to brief, on-site interventions. The most easily attempted approach is an awareness cue. The research presented here will describe an experimental manipulation of awareness cues and its effect on the drinking-and-driving behavior of young people who intend to binge drink. Other novel approaches could attempt to change relevant attitudes, normative pressure, or attractiveness of alternatives. Such approaches are more fully described under future directions for additional research contained in this report.

\section{b. Awareness cues}

Though awareness cues have been used, it is not clear whether they have been thoroughly evaluated. Simons-Morton and Cummings (1997) evaluated a designateddriver program that used server buttons as cues. They measured instances of bar and restaurant patrons drinking nonalcoholic beverages. This is not an ideal measure of designated-driver status; however, as research has demonstrated, some designated drivers do drink alcohol. Further, nonalcoholic consumption is not necessarily an indication of designated-driver status. Regardless, they found that no increased instances of designated driving were observable. However, it is possible that a more sensitive measure of designated-driver status would have identified a difference. Cues may act to prime the concept making it more likely to be used. They, therefore, offer a potential remedy to the "mindlessness" pitfall in two ways. First, it may change the environment sufficiently to cause attention to process that otherwise would have been out of awareness. Second, it can activate concepts that would have otherwise remained dormant. 


\section{F. General methods}

The current experiment was conducted at the San Ysidro border crossing in San Diego County, California. The border between Tijuana and San Diego offers a unique opportunity to recruit young people already intent on binge drinking. Each weekend night (and to a lesser extent on Wednesday nights), thousands of young San Diegans cross the border to patronize bars located just a few blocks into Mexico. Tijuana has an age-18 drinking law, extremely inexpensive drinks, and an atmosphere generally more permissive of intoxication than does San Diego.

Since October 1997, ongoing monthly surveys conducted for the National Institute on Alcohol Abuse and Alcoholism (NIAAA), have been conducted that target San Diegans, ages 18 through 30, heading south on foot into Mexico. This longitudinal survey is conducted on Wednesdays, Fridays, and Saturdays between 10:00 PM and 1:00 AM. Participants are randomly selected; however, entire groups of crossers are recruited both to ensure that participants are not separated from their group of friends and to allow for group-level analyses of data. Random selection is ensured by placing a blue line across the sidewalk and approaching the next group that crosses it as soon as the interviewers are ready. Currently, our longitudinal survey screens for groups containing at least one San Diego County resident between the ages of 18 and 30 . Two additional screens were added to the selection process for the intervention trial discussed here: (1) only groups arriving by noncommercial vehicle, and (2) only groups arriving in no more than half as many vehicles as there are group members. These two screening criteria ensured that the groups asked to participate were able to select a designated driver for each vehicle in their possession.

The existing NIAAA longitudinal survey measures and tracks the motivations and expectations of those planning to binge drink in Tijuana as the San Diego and Tijuana communities implement programs designed to reduce the problem of cross-border binge drinking. The survey is anonymous and includes an alcohol breath test. Participants are given coded bracelets to wear and are instructed that if they check in upon their return, they will receive a $\$ 10$ money order. A hospital-style identity bracelet is used because it cannot be removed without damage. Participants are informed that they will receive $\$ 10$ if they return with the bracelet intact. Upon their return, participants are asked additional questions and, again, given an alcohol breath test. Participants are not specifically informed about the second breath test until they return, though if asked, interviewers do explain that one will be requested but is not required to receive the $\$ 10$. All breath-test devices used are programmed to store BAC results internally (i.e., results can not be viewed) and to display only a subject code.

For the current research project, we used the same methods; however, the survey occurred on a different randomly selected week than the existing survey (referred to here as the longitudinal survey). This eliminated conflicts between the studies and maintained the purity of the longitudinal data being collected under the existing grant. It also allowed the longitudinal survey to act as an additional source of noncued control participants. Using additional staff, surveys were also conducted only on Friday and Saturday nights. The additional staff allowed us to recruit more participants each night than typical. 


\section{Sample characteristics}

Over the 6 nights of survey operations, a total of 455 (149 women, 306 men) people crossing the border on their way into Tijuana agreed to participate. Because intact social groups were recruited, random assignment into the cue or neutral conditions occurred on the group level. Fifty-six groups (207 participants) were assigned to the neutral condition, and 65 groups (248 participants) were assigned into the cue condition. All participants provided breath samples; however, breath-test device malfunctions were recorded for three participants (two were from cued groups, one was from noncued groups). These participants were omitted from the analysis (see Table 1). Three more participants were also omitted because excessive data were missing from their records.

Table 1. Missing and excluded data

Participants recruited crossing into Tijuana

455

Participants excluded because of:

Breath-test malfunction

Excessive missing data

Did not check in with survey staff:

Entire group

Separated group

Passengers whose drivers did not check in: Screening errors

Final sample size

Participants were asked to check in with survey staff upon their return to the U.S. side of the border. After checking in, they were asked additional questions and to give another alcohol breath test. Of the 455 participants, 404 checked in upon their return. Five whole groups of 17 individuals did not return. An additional 34 individuals either were separated from their groups or chose not to check in with their groups.

Because BACs represent the primary dependent variable for the study, those with a missing BAC either upon entry or upon return were not included in the analysis. Imputation of missing cases would have been inappropriate. Thus, both incoming and returning BACs were available for 398 participants. Of these, 7 participants were excluded because the drivers for their groups were among the 34 individuals that did not submit to breath tests upon return. We did not analyze data from passengers when returning $\mathrm{BAC}$ data were not available from their drivers.

Finally, 15 participants were excluded because of screening errors. Screening errors refer to instances where in spite of prescreening potential subjects for appropriateness, some participants admitted that they would not need a designated driver, typically because they had arranged other transportation for getting home.

\section{a. Number of drivers}

Each group was prescreened to have arrived by car, with each car containing at least one passenger. There were, however, some groups that came in several vehicles and, therefore, would have needed more than one driver or designated driver. Each 
driver's status was assessed upon return to the U.S. side of the border during the check-in interview. The remaining groups in the cue condition had 56 drivers and the remaining groups in the neutral condition had 48 drivers.

\section{b. Number of passengers}

There were 130 participants from the cue condition who indicated their intention to be passengers. In the neutral condition, there were 142 such participants.

\section{Standard measures}

Each participant completed a standard set of measures that were used in the longitudinal study (see Appendix A). Table 2 describes the content of both the arrival and departure measures.

Table 2. Measures used in all intervention trials

\begin{tabular}{|l|l|}
\hline Arrival & Departure \\
\hline $\begin{array}{l}\text { Demographics: age, sex, employment, ethnicity, } \\
\text { marital status }\end{array}$ & Demographics \\
\hline Drinking history and prior exposure to Tijuana & Last bar visited \\
\hline $\begin{array}{l}\text { Drinking plans for evening (by individual and by } \\
\text { group) }\end{array}$ & Quantity of alcohol consumed and money spent \\
\hline $\begin{array}{l}\text { Driver or passenger status, and if they own the } \\
\text { vehicle }\end{array}$ & $\begin{array}{l}\text { Means of transportation home, including whether } \\
\text { they are the designated driver, and if they own the } \\
\text { vehicle }\end{array}$ \\
\hline $\begin{array}{l}\text { Attitudes about Tijuana and San Diego's night } \\
\text { scenes }\end{array}$ & $\begin{array}{l}\text { Bad experiences in Tijuana (fighting, victimization, } \\
\text { and encounters with police) }\end{array}$ \\
\hline $\begin{array}{l}\text { Alcohol association scale: A semantic association } \\
\text { measure, with words pairs of "Drunk" and both } \\
\text { positive and negative social words }\end{array}$ & $\begin{array}{l}\text { Designated driver status, and when designation } \\
\text { occurred }\end{array}$ \\
\hline \begin{tabular}{l} 
Alcohol breath test \\
\hline
\end{tabular} & Alcohol breath test \\
\hline
\end{tabular}

\section{Randomized manipulation}

The cue was a question asked orally to a set of participant groups randomly assigned. The question, "Who will be your designated driver tonight?" was posed to half of the randomly selected groups; the question was not posed to the other half. Observations about the manner of designation and the method of selecting participants were also recorded.

\section{G. Results}

\section{Designated-driver use}

Most groups that were cued (87.8\%) indicated the designated driver without discussion, which suggested that the designated driver had been determined beforehand. A smaller percentage (10.2\%) had not determined the designated driver until after being cued, and only one group (2.0\%) indicated that the designated driver was determined in Tijuana. All participants were asked to rate their intentions to drink 
in Tijuana before entering Mexico. As expected by the random-assignment procedure, cued and noncued drivers did not differ significantly in their drinking intentions ( $\mathbf{p}<83$ ) because their rating occurred before the cue manipulation.

Upon returning to San Diego, participants (whether cued or not) were asked how they were getting home and whether or not they were a designated driver. Results suggest that use of designated drivers in these groups was high. Only 1 of the 104 returning groups did not have someone who identified himself or herself as a designated driver. This identification rate is similar to our findings in the longitudinal study of the border crossers. This new research has also found almost universal identification of designated drivers upon return. Of course, the problem is that, in spite of this designation, many of the drivers had been drinking, and some were even at levels that would be in violation of California's per se limit of .08 for adults. So clearly, the mere acceptance of the label of designated driver is not sufficient to use as a measure of cue effects.

Examination of cued designated drivers revealed that $81.3 \%$ had apparently been assigned that role before entering Tijuana. Further, $87.3 \%$ of those who earlier had been appointed as designated drivers by their groups did in fact act as the designated drivers upon return. This suggests that though a large percentage of appointed designated drivers fulfilled this obligation, only a small percentage of groups switched designated drivers during the evening. An examination of the BACs of returning designated drivers, both those who maintained the role of designated driver and those who did not, is presented in the following section.

\section{BACs of returning designated drivers}

Although only one applicable group failed to indicate a designated driver is encouraging, understanding the responsibilities befalling designated drivers was less encouraging as the definitions varied considerably among individuals. For some, being a designated driver meant abstaining from alcohol; for others, being a designated driver implied being the least intoxicated person in a group. Some even thought being the designated driver was as simple as being the owner of the vehicle. Therefore, it is important to examine the BACs of crossers, not simply whether or not they claimed designated-driver status.

The first analysis investigated the BACs of those participants who initially indicated that they were designated drivers but who had switched to passenger status during the course of the night. Only participants in the cued condition are included in this analysis because records of the designated-driver status were not available for noncued groups. Participants who were initially assigned the role of designated driver but who did not act as designated driver upon return had significantly higher BACs $\left(\mathrm{M}^{1}=.05\right)$ than did participants who both were initially assigned that role and who acted as designated driver upon return $(\mathrm{M}=.01), \underline{\mathrm{F}}(1,52)=6.33, \mathrm{p}<.05^{2}$. Members of groups in the cued condition appeared to be sensitive to the alcohol consumption of their designated drivers.

${ }^{1} \mathrm{M}$ represents the arithmetic mean (average)

2 This analysis statistically controlled for participants' BACs as they entered Tijuana. 


\section{a. Effect of cue}

Additional analysis examined the interaction between cue condition and gender on drivers' BACs controlling for incoming BACs. Gender was included in this design because it is both an important predictor of the returning $\mathrm{BAC}$ and because previous research at the border indicated that the designated-driver status seemed to predict lower BACs only among female crossers. The results revealed no statistically significant main effects for cue condition (cued drivers' BAC $=.01$; noncued drivers' $\mathrm{BAC}=.02, N S)$. There was neither a statistically significant main effect for gender nor a statistically significant interaction between gender and cue condition (all ps>.40).

\section{BACs of returning passengers}

Because multiple passengers often came from the same group, we could not conclude that the statistical assumption of independent observations held true. Therefore, an analysis of passenger BACs was conducted using Hierarchical Linear Modeling (HLM) for Windows software version 4.01.01 (Bryk, Raudenbush \& Congdon, 1996). This analysis accounts for effects attributable to differences between individual groups. HLM for Windows was used to test the interaction between cue condition and gender on returning passengers' BACs, controlling for incoming passengers' BACs. This analysis allowed for random group intercepts but treated level-1 predictors as fixed.

The results revealed that mean returning BACs varied significantly among groups, $\mathrm{X}^{2}(103)=240.92, \mathrm{p}<.01$. Furthermore, the mean returning BACs of male passengers $(M=.05)$ was significantly higher than for female passengers $(M=.04), \underline{t}=2.41, p<.02$. However, neither the main effect for cue condition nor the interaction between cue and gender approached statistical significance (ps>.50). Figure 2 presents the returning BACS.

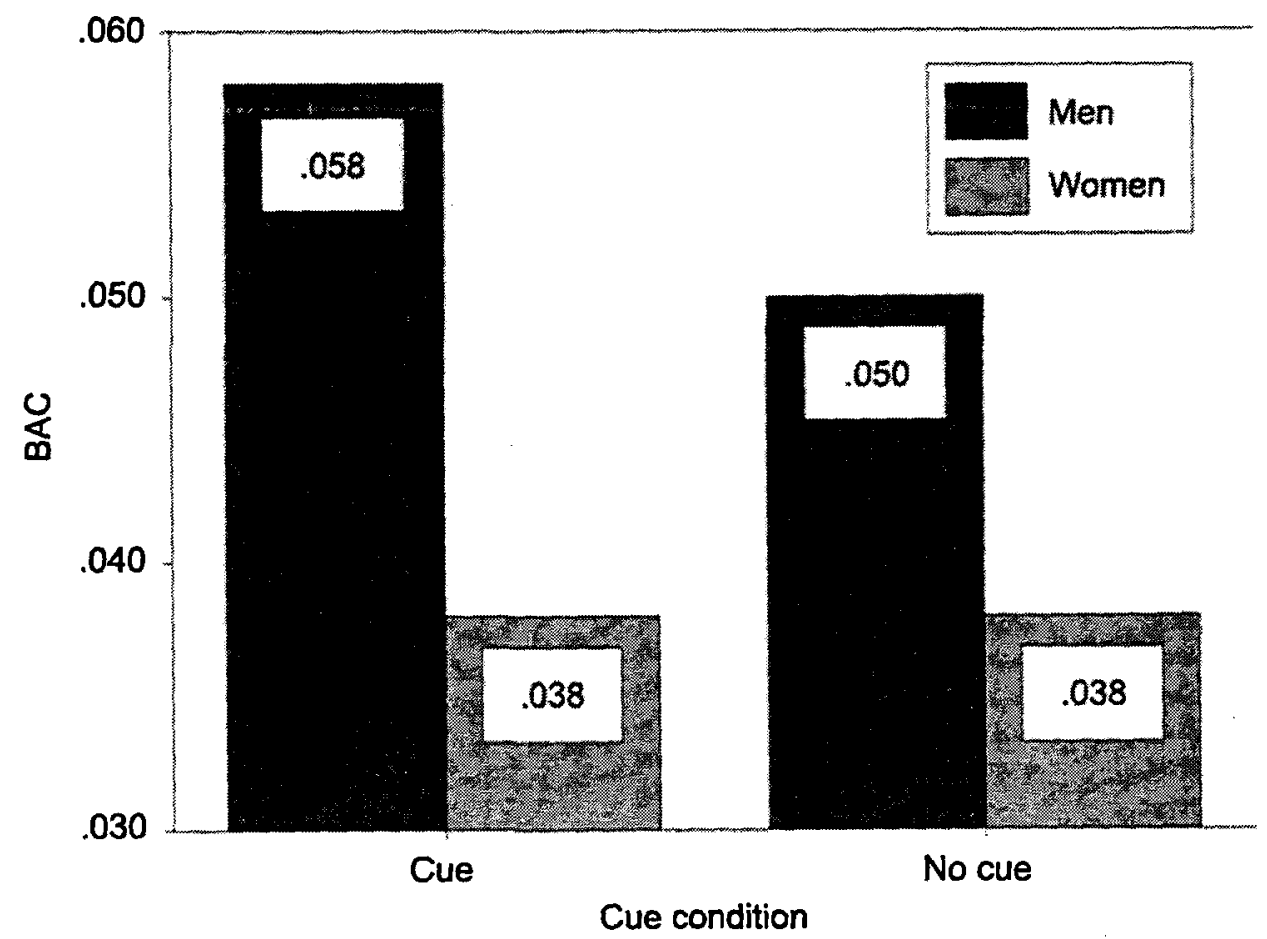

Figure 2. Returning BACs (Mean/Average) 


\section{H. Discussion}

The results indicate that the cue had little effect on the BACs of returning drivers or passengers. Although returning cued drivers had slightly lower BACs than returning noncued drivers this trend was statistically insignificant. Passengers, too, exhibited slight differences with the trend being towards higher BACs among cued passengers. However, again, this trend was not statistically significant. One unfortunate complication of these analyses is that although they were randomly assigned, cued crossers arrived at the border with significantly higher BACs than noncued crossers. This meant that BACs upon arrival had to be included in all analyses, thus making interpretation of results more difficult.

Interestingly, several groups switched designated drivers during the evening. Though these groups apparently chose more sober drivers, it indicates the misuse of the designated-driver concept because it is critical for the driver to maintain his or her status. What is unclear is whether the change in designation occurred because of drivers' drinking behavior or if the change in designation permitted the heavier drinking.

Possibly, the equivocal results of merely cueing the concept of designated drivers for crossers intending to drink in Tijuana stems from the almost universal claim of using the designated-drive concept regardless of cueing. Although cueing was intended to activate a schema not already in use, almost all crossers had thought about the concept already; therefore, the impact may be seriously diminished. However, just because participants claimed to be already using designated drivers, many of these crossers misapplied the concept. As cueing did not affect the implementation of the concept beyond the identification of the driver before drinking, the misapplication continues in spite of the intervention.

\section{Future Directions}

The results of this preliminary study, which used only the most simple, brief intervention for those crossing into Tijuana to visit bars, seem to point toward the need to design interventions with more impact to address key components in properly using designated drivers. Interventions that have an impact on attitudes, normative pressures, and attractiveness of alternatives may have more effect on driver's drinking behaviors than mere awareness manipulation.

\section{a. Cueing-at drinking point}

Although the previous intervention cued participants to select a designed driver, it is also reasonable to provide cues at the point of drinking. As already discussed, there are three stages for implementing the designated-driver concept. The stage following the designation involves limiting drinking. There may be several impediments to remaining sober after the designation is made. Normative pressure and expectations for alcohol are two such impediments. One simple way to intervene at this point will be to remind participants of the designated driver's commitment to remain sober. For some, this should encourage the driver to limit drinking. The use of bracelets with the words "designated driver" worn by the driver may be sufficient to keep the concept within his or her awareness at the drinking locale. Drinking locales may also provide environmental cues, such as signs or soft-drink specials for the designated driver. 


\section{b. Attitude change}

The cueing interventions rely on the relative positive assessment of the designateddriver concept to function. If participants' attitudes about the designated-driver concept are negative, then activating the concept will not help. For these participants, it will be necessary to alter their attitudes, at least enough to make them more receptive to this concept than to the alternative of driving impaired.

Research has demonstrated that there are several channels for persuasion (e.g., Petty \& Cacioppo, 1986). The border, as at most drinking locales, is probably more suited for peripheral routes since the motivational state of patrons is not one that likely favors cognitive complexity. In other words, it offers little opportunity for a rational or "central route" approach. Therefore, it is more practical to apply a "peripheral" route such as a dissonance approach. Such an intervention could make participants aware of cognitive inconsistencies and perhaps hypocrisies to motivate change (see Aronson, Fried, \& Stone, 1991). One approach could have the designated-driver participant read to his or her group a positive statement about designated drivers and a negative statement about driving drunk. The participant would be given an additional reward for doing so, though the reward will be small enough so that most would consider it insufficient to make them read a counter-attitudinal message. Further, we could attempt to persuade the driver to identify the hypocrisy within their previous actions and the statement they had just read by asking about his or her last experience as a designated driver.

\section{c. Attractiveness of alternative change-rewards}

Environmental controls usually increase the cost, either real or potential, for drunk driving. However, we can also hypothesize that increasing the rewards of not-drinkingand-driving will also have an effect. Therefore, an intervention could be conducted that offers to reward designated-driver participants if they return with BACs no greater than .01 (the level usually used for zero tolerance enforcement). Such a design would have to be sensitive to human subjects concerns, specifically the need for breath test results to be nonaccessible at the test site.

\section{d. Normative pressure}

One of the significant impediments identified in the introductory section of this report was the normative pressure placed on the designated-driver participant to sabotage his or her efforts to remain alcohol free. A driver will witness friends and others around them consuming alcohol. Bartenders may offer him or her drinks, as could other patrons or friends. Under these circumstances, it would not be surprising if even the best-intentioned designated-driver participant drinks.

It is, therefore, reasonable to seek to change the immediate social environment to support, rather than subvert, the sobriety of the driver. To do this, group members must be motivated to discourage driver drinking. A reward system could be created to support the abstinence of the driver. For instance, all group members in the treatment condition, in addition to the driver, could be offered a reward if the driver returns with a BAC no greater than .01 . 


\section{e. Normative pressure through attitude change}

Rewards can motivate group members to encourage designated-driver sobriety increasing the attractiveness of being a designated driver and, therefore, decreasing the likelihood that the driver will return with a high BAC. However, such an intervention should have few lasting effects (especially as a one-time trial) because, without the reward, the costs of being a designated driver may again outweigh the rewards. Therefore, an alternative way to change group norms that rely on persuasion may be more desirable. Further, rewards are an expensive option for motivating groups and, therefore, may be less attractive than other, less costly interventions.

Therefore, an intervention similar to the attitude-change manipulation discussed above could be modified to include all group members. Instead of asking the designated-driver participant to read aloud a potentially counter-attitudinal message, a group member could be asked to read the statement. Again, the level of incentive would be designed to appear insufficient to participants. We hypothesized that, at least for that group member, dissonance will be experienced if he or she allows the driver to drink after reading the statement.

\section{Final comments}

This report has outlined the theoretical impediments to the proper implementation of the designated-driver concept. It has also reported on an experimental trial that attempted to increase the use of designated drivers by cueing potential drinkers heading into Mexico to visit the bars of Tijuana. Though that experimental manipulation proved to be insufficient to effect a change in the drinking behavior of those who would drive, it did highlight the feasibility of experimentally testing brief interventions designed to reduce drunk driving. As additional interventions are attempted, we will gain a better understanding of the particular importance of specific impediments to the use of designated drivers as well as the effect of designated drivers on the drinking behavior of passengers. 


\section{References}

Aitken, P. P. (1985). An observational study of young adults' drinking groups-II. Drink purchasing procedures, group pressures and alcohol consumption by companions as predictors of alcohol consumption. Alcohol and Alcoholism, 20(4), $445-457$.

Apsler, R. (1989). Transportation and alcohol service policies: Transportation alternatives for drinkers. In Surgeon General's workshop on drunk driving: Background papers, Washington, DC, December 14-16, 1988. (pp. 157-168). Rockville, MD: U.S. Department of Health and Human Services, Public Health Service, Office of the Surgeon General.

Apsler, R., Harding, W., \& Goldfein, J. (1987, February). The review and assessment of designated driver programs as an alcohol countermeasure approach. (Final Report HS 807 108). Washington, DC: U.S. Department of Transportation, National Highway Traffic Administration.

Aronson, E., Fried, C., \& Stone, J. (1991). Overcoming denial and increasing the intention to use condoms through the induction of hypocrisy. American Journal of Public Health, 81(12), 1636-1638.

Asch, S. E. (1951). Effects of group pressure upon the modification and distortion of judgments. In H. Guetzkow (Ed.) Groups, leadership, and men. Pittsburg: Carnegie Press.

Billings, C. E., Gerke, R. J., \& Wick, R. L. (1972). Comparisons of pilot performance in simulated and actual flight. Aviation, Space and Environmental Medicine, 46, 304-308.

Binder, A. (1971). An experimental approach to driver evaluation using alcohol drinkers and marijuana smokers. Accident Analysis and Prevention, 3, 237-256.

Brehm, J. W. (1972). Responses to loss of freedom: A theory of psychological reactance. Morristown, NJ: General Learning Press.

Bruun, K. (1959). Drinking behavior in small groups. (Vol. 9). Helsinki: Finnish Foundation for Alcohol Studies.

Bryk, A., Raudenbush, S., \& Congdon, R. (1996). HLM: Hierarchical linear and nonlinear modeling with the $H L M / 2 L$ and $H L M / 3 L$ programs. Chicago, IL: Scientific Software International, Inc.

Caudill, B. D., \& Marlatt, G. A. (1975). Modeling influences in social drinking: An experimental analogue. Journal of Consulting and Clinical Psychology, 43(3), 405-415.

Chaiken, S. (1980). Heuristic versus systematic information processing and the use of source versus message cues in persuasion. Journal of Personality and Social Psychology, 39, 752-766. 
Collins, R. L., Parks, G. A., \& Marlatt, G. A. (1985). Social determinants of alcohol consumption: The effects of social interaction and model status on the selfadministration of alcohol. Journal of Consulting and Clinical Psychology, 53(2), 189-200.

Cooper, A. M., Waterhouse, G. J., \& Sobell, M. B. (1979). Influence of gender on drinking in a modeling situation. Journal of Studies on Alcohol, 40(7), 562-570.

DeJong, W., \& Wallack, L. (1992). The role of designated driver programs in the prevention of alcohol-impaired driving: A critical reassessment. Health Education Quarterly, 19(4), 429-442.

DeJong, W., \& Winsten, J. A. (1990). The Harvard alcohol project: A demonstration project to promote the use of the "designated driver". In Proceedings of the 11th International Conference on Alcohol, Drugs and Traffic Safety. Chicago, IL: National Safety Council.

Fell, J., Voas, R. B., \& Lange, J. E. (1997). Designated driver concept: Extent of use in the USA. Journal of Traffic Medicine, 25(3-4), 109-114.

Glascoff, M. A., Knight, S. M., \& Jenkins, L. K. (1994). Designated-driver programs: College students' experiences and opinions. College Health, 43, 65-70.

Harding, W. M., Apsler, R., \& Goldfein, J. (1998, January). A directory of ride service programs. (Final Technical Report DOT HS 807 290). Washington, DC: U.S. Department of Transportation, National Highway Traffic Safety Administration.

Harding, W. M., \& Caudill, B. D. (1997). Does the use of designated drivers promote excessive alcohol consumption? In C. Mercier-Guyon (Ed.) Proceedings of the 14th Annual Conference on Alcohol, Drugs and Traffic Safety, Volume 3. Annecy, 21 - 26 September, 1997. (pp. 1359-1364). Annecy, France: Centre d'Etudes et de Recherches en Médecine du Traffic.

Hennessy, M., \& Saltz, R. F. (1993). Modeling social influences on public drinking. Journal of Studies on Alcohol, 54(2), 139-145.

Hull, J. G., Levenson, R. W., Young, R. D., \& Sher, K. J. (1978). Self-awareness reducing effects of alcohol consumption. Journal of Personality and Social Psychology, 44, 461-473.

Kelley, H. H., \& Michela, J. L. (1980). Attribution theory and research. Annual Review of Psychology, 31, 457-501.

Knight, S. M., Glascoff, M. A., \& Rikard, G. L. (1993). On being a designated driver: A qualitative investigation of underage college student perceptions. Journal of College Student Development, 34, 425-431.

Lange, J. E. \& Voas, R. B. (2000). Youth escaping the limits on drinking: Binging in Mexico. Addiction, 96(4).

Lange, J. E., Voas, R. B., \& O'Rourke, P. (1998). What is a designated driver anyway? Results of a California survey on definitions and use of designated drivers. Journal of Traffic Medicine, 26(3-4), 101-108. 
Langer, E. J. (1989). Mindfulness. Reading, MA: Addison-Wesley.

Lau, M. A., Pihl, R. O., \& Peterson, J. B. (1995). Provocation, acute alcohol intoxication, cognitive performance, and aggression. Journal of Abnormal Psychology, 104, 150-155.

Leid, E. R., \& Marlatt, G. A. (1979). Modeling as a determinant of alcohol consumption: Effect of subject sex and prior drinking history. Addictive Behaviors, 4, 47-54.

McKnight, A. J., Lange, J. E., \& McKnight, A. S. (1995). Why people drink and drive: The basis of drinking-and-driving decisions. In C. N. Kloeden \& E. McLean (Eds.). Alcohol, drugs, and traffic safety. (Vol. 1, pp. 143-147). Adelaide, Australia: NHMRC, University of Adelaid.

Moskowitz, H. (1973). Laboratory studies of the effects of alcohol on some variables related to driving. Journal of Safety Research, 5(3), 185-199.

Moskowitz, H., Burns, M. M., \& Williams, A. F. (1985). Skills performance at low blood alcohol levels. Journal of Studies on Alcohol, 46(2), 482-485.

Petty, R. E., \& Cacioppo, J. T. (1986). The elaboration likelihood model of persuasion. In L. Berkowitz (Ed.) Advances in experimental social psychology. (Vol. 19, pp. 123-205). New York: Academic Press.

Reid, J. B. (1978). Study of drinking in natural settings. In G. A. Marlatt \& P. E. Nathan (Eds.). Behavioral approaches to alcoholism. (pp. 58-74). New Brunswick: Rutgers Center of Alcohol Studies.

Room, R. (1975). Normative perspectives on alcohol use and problems. Journal of Drug Issues, 5, 358.

Ross, H. L. (1992). Confronting drunk driving: Social policy for saving lives. New Haven, CT: Yale University Press.

Shore, E. R., Gregory, T., \& Tatlock, L. (1991). College students' reactions to a designated driver program: An exploratory study. Journal of Alcohol and Drug Education, 37(1), 1-6.

Simons-Morton, B. G., \& Cummings, S. S. (1997). Evaluation of a local designated driver and responsible server program to prevent drinking and driving. Journal of Drug Education, 27(4), 321-333.

Single, E. (1996). Harm reduction as an alcohol-prevention strategy. Alcohol Health \& Research World, 20(4), 239-243.

Steele, C. M., \& Southwick, L. (1985). Alcohol and social behavior I: The psychology of drunken excess. Journal of Personality and Social Psychology, 48, $18-34$.

Sykes, R. E., Rowley, R. D., \& Schaefer, J. M. (1990). Effects of group participation on drinking behaviors in public bars: An observational survey. In J. W. Neuliep (Ed.) Journal of Social Behavior and Personality, Handbook of Replication Research (Special Issue). (Vol. 5, 4, pp. 385-402).

The Roper Organization. (1991). Roper reports, 91(3), 19-20. 
Turrisi, R., \& Jaccard, J. (1992). Cognitive and attitudinal factors in the analysis of alternatives to drunk driving. Journal of Studies on Alcohol, 53, 405-414.

van de Goor, L. A. M., Knibbe, R. A., \& Drop, M. J. (1990). Adolescent drinking behavior: An observational study of the influence of situational factors on adolescent drinking rates. Journal of Studies on Alcohol, 51(6), 548-555.

Wagenaar, A. C. (1992). Designated driver programs: A commentary on the DeJong and Wallack article. Health Education Quarterly, 19(4), 443-445.

Werch, C. E. (1990). Behavioral self-control strategies for deliberately limiting drinking among college students. Addictive Behaviors, 15, 129-135.

Werch, C. E., \& Gorman, D. R. (1988). Relationship between self-control and alcohol consumption patterns and problems of college students. Journal of Studies on Alcohol, 49(1), 30-37. 


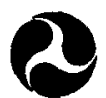

U.S. Department

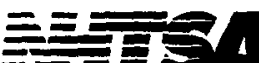

National Mighuray $\equiv$ Poots soving Parrs

Trafitic Solety

wrmiltendetery

DOT HS 809178

July 2000 